\title{
USE OF RECYCLED AGGREGATES FROM DEMOLITION WASTES IN CONCRETE: ACOUSTIC PROPERTIES
}

\author{
CARLOS RODRÍGUEZ ${ }^{1}$, ISIDRO SÁNCHEZ ${ }^{2}$, SALVADOR MARTÍNEZ ${ }^{1}$, \\ JESÚS CARBAJO ${ }^{3}$, JAIME RAMIS ${ }^{3}$ \& IGNACIO GARCÍA-LEGAZ ${ }^{1}$ \\ ${ }^{1}$ Technological Centre of the Construction of Region of Murcia, Spain \\ ${ }^{2}$ Department of Civil Engineering, University of Alicante, Spain \\ ${ }^{3}$ Department of Applied Physics, University of Alicante, Spain
}

\begin{abstract}
The construction industry is one of the most demanding in terms of natural resources, and of the most polluting in terms of emissions to the atmosphere. Concrete is one of the most used materials in engineering and is a paradigm of the consumption of rocks for aggregates, used in polluting industries such as cement production. In trying to reduce the consumption of natural resources, efforts are being made to use waste as recycled aggregates. This fact has evident economic and environmental advantages, but it has a drawback. The concrete prepared with recycled aggregates has lower mechanical strength than ordinary concrete. This decrease of resistance is mainly due to a higher porosity exhibited by the materials from recycled aggregates. But the increase of porosity can be a great advantage in terms of sound absorption. In this work several types of recycled aggregates have been tested, paying special attention to their acoustic behaviour and pore structure. The results show that concrete made with recycled waste are effective in absorbing sound. It might become an alternative to traditional concrete, since recycling samples behave similarly or better in terms of sound absorption, using recycled materials, and increasing their life-cycle. The measurement of acoustic properties, as well as density, has already been undertaken in previous works. This work presents an image analysis methodology that is completely novel, and that helps to understand the acoustic behaviour of concrete elements.
\end{abstract}

Keywords: recycled aggregates, pore structure, sound absorption.

\section{INTRODUCTION}

In recent history the development has mainly considered economic aspects. Nowadays the trends are changing towards a more sustainable development, in a circular economy model, with a reduction of natural resources, and decreasing the generated wastes. In this context, construction and demolition wastes have a great value, due to the huge volume generated, and that offered a great possibility of recycling. In this sense the European Parliament has stated the need of reusing these wastes to promote a more sustainable construction [1].

The Spanish standard for structural concrete promotes the use of these residues as aggregates, but for the case of structural concrete it is limited to a $20 \%$ (with no risk for the structural integrity), and to wastes containing only concrete [2]. The real fact is that most demolition wastes contain many other materials such as ceramics, asphalt, etc. Those wastes (recycled mixed aggregate, RMA) could not be used, according to the Spanish standard, even for non-structural concrete. This makes the recycling rates very low in Spain [3], [4]

However, many efforts are being made for producing non-structural elements of concrete, containing recycled aggregates, even at industrial scale [5]. In these works, the mechanical properties, some durability aspects are determined. It is a common fact that the use of recycled aggregates causes a decrease of the compressive strength depending on the type of recycled aggregate used. Some studies show that it is possible to use up to $50 \%$ of recycled concrete aggregates with no loss of mechanical properties [6], but samples prepared with RMA (a mix of construction and demolition wastes, with almost no classification) may cause an important decrease of the properties of concrete [7]. This fact is the reason why most of 
the elements prepared are non-structural elements [5], [8], [9]. The origin of the mechanical loss is mainly due to the greater porosity produced by the recycled aggregates, either because of the higher porosity of recycled aggregates [8], or because of the greater interfacial transition zone (ITZ) among paste and aggregate, due to the presence of undesired materials in the aggregates [10], [11]. In both cases the porosity of concrete increases, and it causes the loss of properties.

This increase in porosity can be an advantage in terms of sound absorption. To that end, different types of recycled materials (construction and demolition wastes) have been used to prepare concrete with recycled aggregates. They have been tested to establish acoustic properties, mainly, and to establish if the recycled samples have similar, or improved the acoustic behaviour of samples prepared with natural aggregates.

\section{EXPERIMENTAL SETUP}

In this section both the materials prepared, and the techniques used will be described.

\subsection{Materials}

Concrete samples were prepared using an ordinary Portland cement, CEM I 42.5R according to the standard [12], and the w:c ratio used was of 0.58 . The dosage used for each element prepared follows the proportions given in Table 1.

Table 1: Concrete dosage used for every mix prepared.

\begin{tabular}{|l|c|}
\hline Material & $\%$ in mass \\
\hline Cement & 7.4 \\
\hline Water & 4.3 \\
\hline Limestone filler & 0.8 \\
\hline Fine aggregate $(0-4 \mathrm{~mm})$ & 10.55 \\
\hline Coarse aggregate $(2-6 \mathrm{~mm})$ & 76.95 \\
\hline
\end{tabular}

Only the coarse fraction of the aggregates was replaced by recycled materials. The materials used to substitute the natural aggregates are recycled arlite, asphalt, ceramic, ethylene-vinyl acetate (EVA), hollow tiles, recycled concrete and rubber. The materials were crushed, some of them in a laboratory crusher, and the other provided by the suppliers of the wastes. The materials were selected to have dimensions in the indicated range, and to have a similar grain size distribution, compared with natural aggregates. The arlite is not a recycled aggregate, but since it is a very porous aggregate, it was included to grain size distributions of selected aggregates are shown in Fig. 1. The replacement of the coarse fraction was total, and all the aggregates were water saturated and surface dried prior to mixing, to ensure the hydration water for the cement. Samples were cast in molds with dimensions $50 \mathrm{~mm}$ height and $70 \mathrm{~mm}$ diameter and kept in humid chamber for 28 days. Only half of the samples were compacted with a manual procedure, compacting by layers using a steel bar, while the other half suffered no compaction. Non-compacted samples were only prepared with the natural aggregate, arlite, asphalt, ceramics, and hollow tiles wastes. The differences are evident and can be appreciated in Fig. 2. The sample that suffered no compaction presents a much more porous structure. Six samples of each type were prepared for testing. 


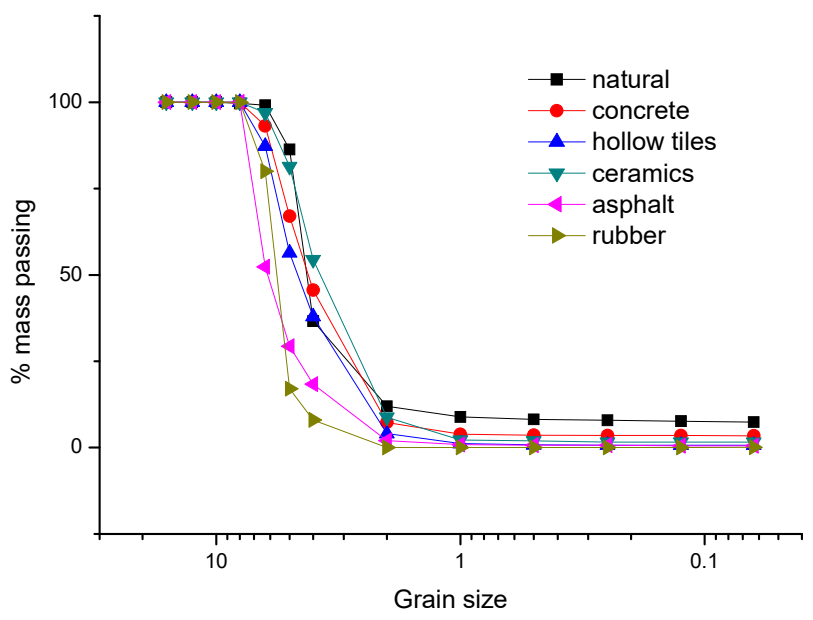

Figure 1: Grain size distribution of selected aggregates for the preparation of concrete.

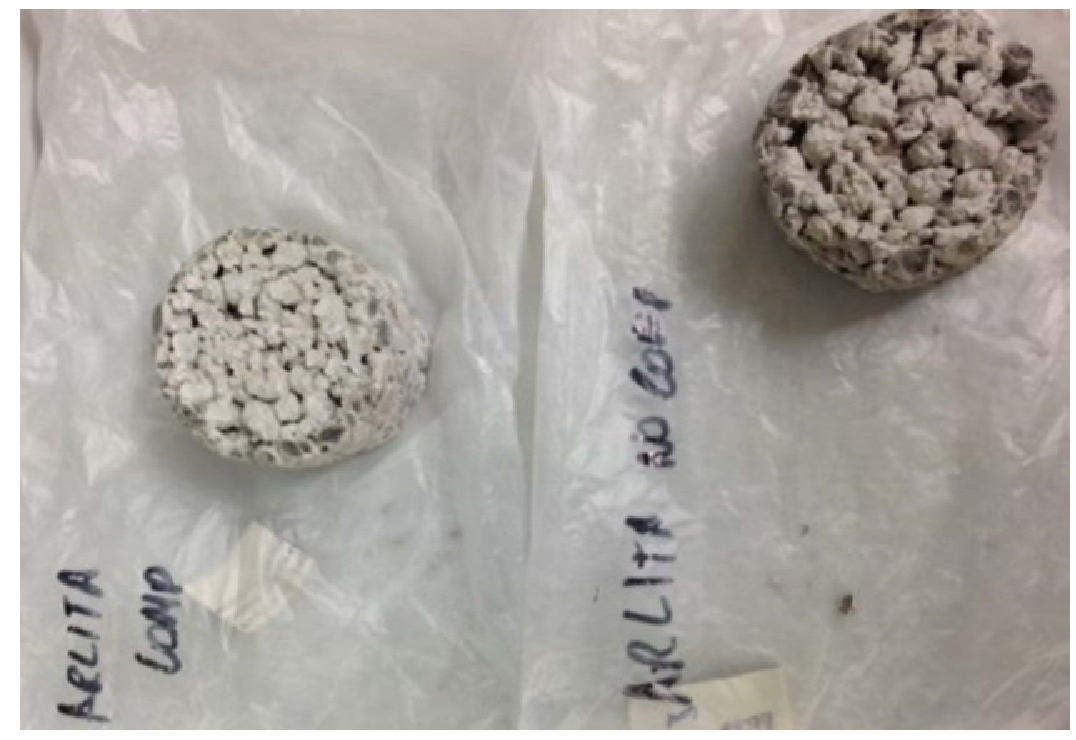

Figure 2: Prepared samples using arlite as aggregate. The sample on the left was manually compacted, while the sample at the right suffered no compaction.

\subsection{Testing procedures}

The samples were tested to obtain the acoustic properties. Initially the bulk density and fraction of holes were determined using the hydrostatic balance method [13]. The sound absorption was determined using the impedance tube method [14] and the absorption coefficient was determined in the frequency range from 250 to $2,600 \mathrm{~Hz}$. In order to try to understand the behaviour of the materials an image analysis has been done on samples. 


\subsubsection{Image analysis}

Samples were coloured on their surface, by letting them lay on a coloured surface, to avoid paint penetration, and let them dry. The result is shown in Fig. 3(a). After that a 3 step methodology is followed to analyse the pore structure:

The process to make the analysis was in three steps:

Step 1: Capture of the photographs in a controlled situation of light, using the same focal length, and diaphragm opening.

Step 2: Treatment of the photographs to clean all the parts that do not belong to the sample. Step 3: Use the program ImageJ to analyse the photos and get all the information about holes and surfaces. The program uses filters to separate the different parts, for this study we have decided to use three filters, one for the deep holes, one for the plane surface, and one for the rest of the surfaces. The parameters used for each one of the filters are reported in Table 2. The results of the application of the subsequent filters to the image are presented in Fig. 3(b)-(d).

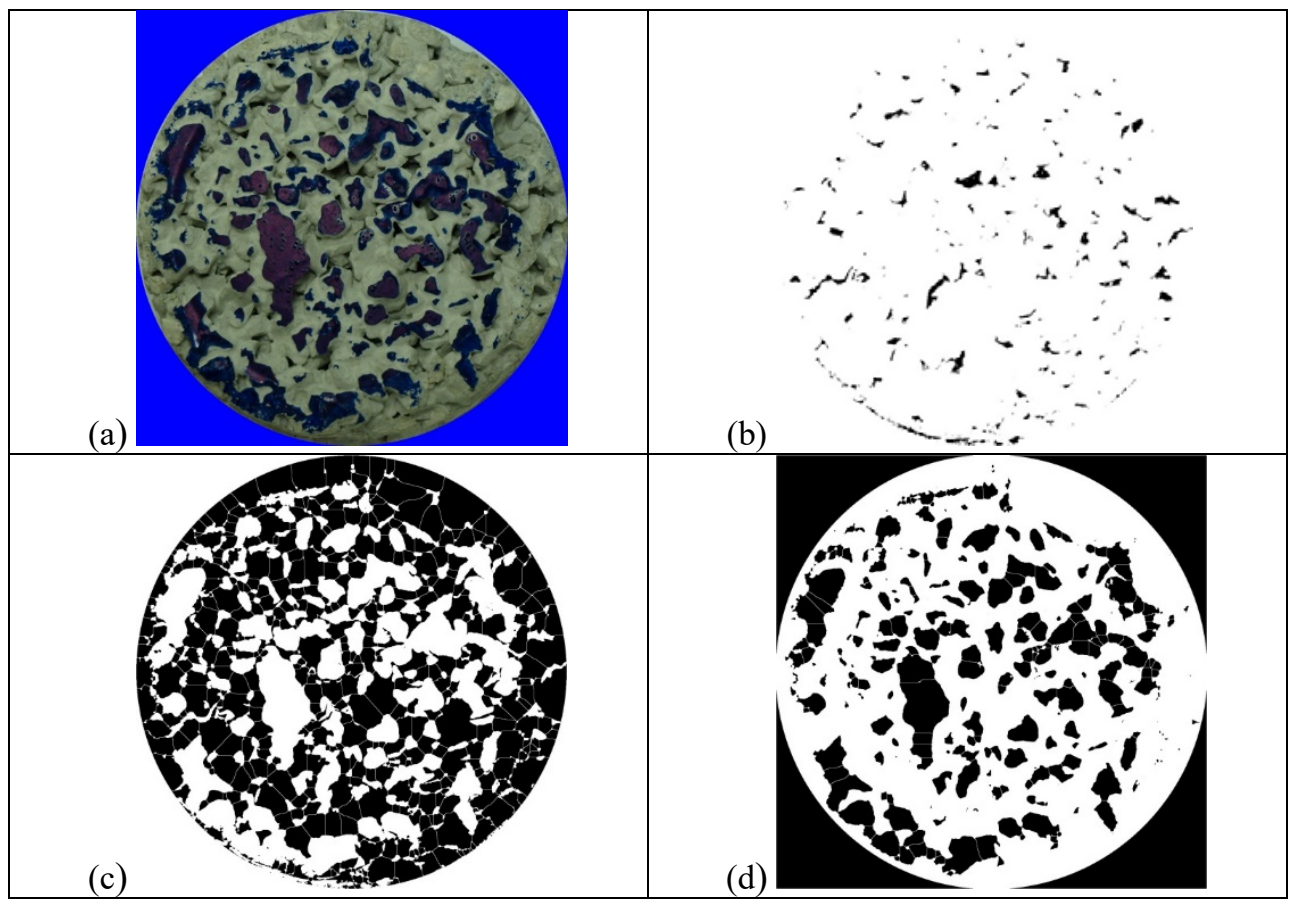

Figure 3: Example of the image analysis done on the coloured samples: (a) For the original picture taken of the coloured sample; (b) After applying filter 1; (c) After applying filter 2; and (d) After applying filter 3.

The first filter selects the deep holes that appear in the image. Before applying the filters, the noise, that appears as small black dots, was also removed. The filters were selected after several trials, the first one corresponded to the surface, that was coloured, and it was very easy to determine, in second place the darkest parts of the image, that correspond to the 
Table 2: Parameters used for each filter used in the image analysis.

\begin{tabular}{|l|c|c|c|}
\hline & Colour & Saturation & Brightness \\
\hline Filter 1 & $0-116$ & $0-255$ & $0-70$ \\
\hline Filter 2 & $0-116$ & $0-255$ & $70-255$ \\
\hline Filter 3 & $116-255$ & $0-255$ & $0-255$ \\
\hline
\end{tabular}

deepest holes in the sample were identified, and the last filter studied the intermediate zone, that corresponds to pores, but that are not too deep. So, the three different parts in which the image is divided were analysed to obtain an idea of the pore network. The abovementioned program (ImageJ) draws the perimeter of the surfaces with the same colour and calculates the perimeter and the surface of each element, that is identified with a number.

\section{RESULTS AND DISCUSSION}

\subsection{Density and porosity}

As was explained, these parameters were determined according to the UNE-EN 12390-7 standard [13]. The average results are shown in Table 3.

Table 3: Parameters for each filter used in the image analysis.

\begin{tabular}{|l|c|c|c|}
\hline \multirow{2}{*}{ Material } & $\begin{array}{c}\text { Bulk density } \\
\left(\mathrm{g} / \mathrm{cm}^{3}\right)\end{array}$ & Porosity, \% & Compacted \\
\hline \multirow{2}{*}{ Reference } & \multirow{2}{*}{ Arlite } & 35.1 & No \\
\cline { 3 - 4 } & \multirow{2}{*}{ Asphalt } & 31.77 & Yes \\
\cline { 3 - 4 } & \multirow{2}{*}{2.40} & - & No \\
\cline { 3 - 4 } Ceramic & \multirow{2}{*}{1.90} & 37.36 & Yes \\
\hline EVA & - & 39.45 & Yes \\
\hline \multirow{2}{*}{ Hollow tiles } & 2.46 & 32.88 & No \\
\hline Recycled concrete & 2.27 & 27.57 & Yes \\
\hline Rubber & - & 32.07 & Yes \\
\hline
\end{tabular}

As a first result it can be noticed that the density and pore volume fraction could not be measured due to the standardized method used, that implies immersion under water. The bulk density shows no variation from compacted to non-compacted samples, as it could be expected since all the samples came from the same mix. The reference concrete has high density, but the samples prepared with fractions of hollow tiles show a slightly higher density, possibly due to the compaction method usually applied to these elements (vibropressing) [5]. The samples prepared with ceramic aggregates exhibits the lowest porosity among those which allowed density measurement. This fact is quite common, due to the high porosity measured in ceramic aggregates in previous works [8], [15]. The elements prepared with arlite, EVA and rubber showed a density lower than water, and this did not allow the proper determination of the density. 
Regarding the void fraction measured for each sample, the non-compacted samples exhibit a clearly higher pore fraction than the compacted ones for the same type of waste, as could be expected. Among the compacted samples the highest porosity is shown by the samples prepared with ceramic aggregates, in coincidence with the bulk density results. This fact confirms the theory of the influence of the highest porosity of ceramic aggregates on the properties of the concrete elements. Only compacted samples prepared with hollow tiles wastes and asphalt wastes have shown a slightly smaller porosity that the reference element, again possibly due to the compaction methods used for hollow tiles. The result for asphalt would need more in depth research, but it could be due to the adherence of the organic phase of the asphalt to the aggregate used. The non-compacted samples exhibit a quite different behaviour. Non-compacted samples prepared with ceramics and asphalt wastes are the only ones showing a higher porosity as compared to the non-compacted reference material. This could be possibly due to the highest porosity of ceramic samples, and also to the difficulty of paste flowing through the aggregates, due to their characteristics, that could increase the viscosity. Other option in the case of asphalt is the presence of a greater ITZ, that will cause a decrease of porosity when samples are not properly compacted [16]. The rest of the samples showed a lower porosity, possibly due to a better compaction, or a more compact ITZ due to the similarity of the cement mortar and the aggregates (in the case of hollow tiles and recycled concrete), or to the different granulometric distribution exhibited by rubber wastes that allow the mortar to flow through the grains of aggregate, as it has been already reported with the presence of coarse asphalt particles [17].

\subsection{Acoustic properties}

The plots for the sound absorption coefficient in the measured range can be seen in Fig. 4 for compacted samples and Fig. 5 for non-compacted samples.

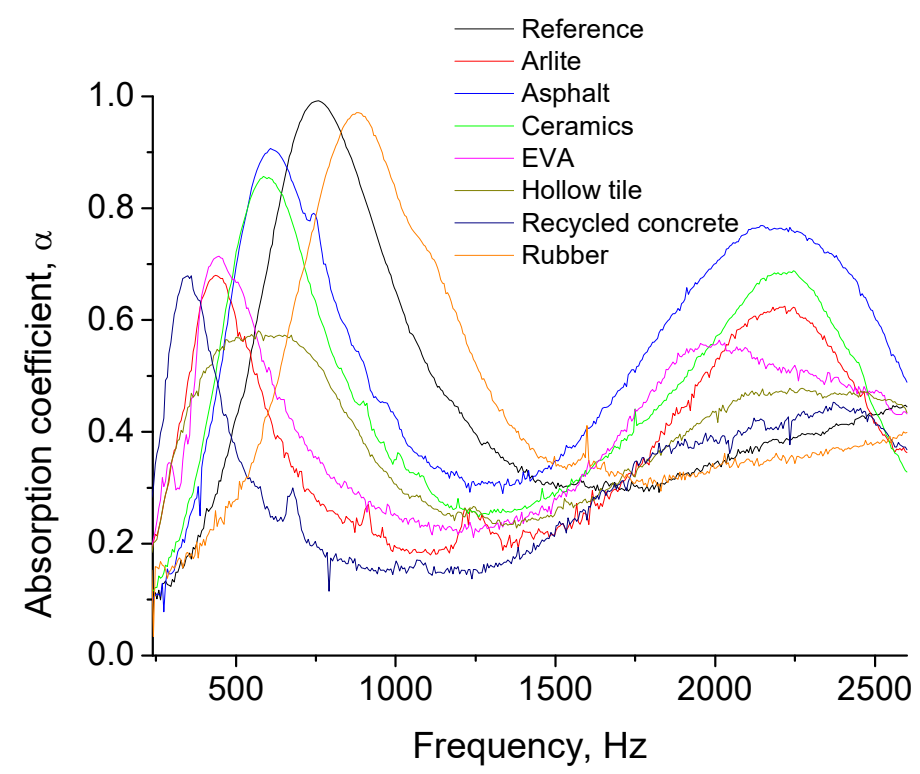

Figure 4: Absorption coefficient in the studied range of the compacted concrete samples prepared with each type of aggregates (including reference). 


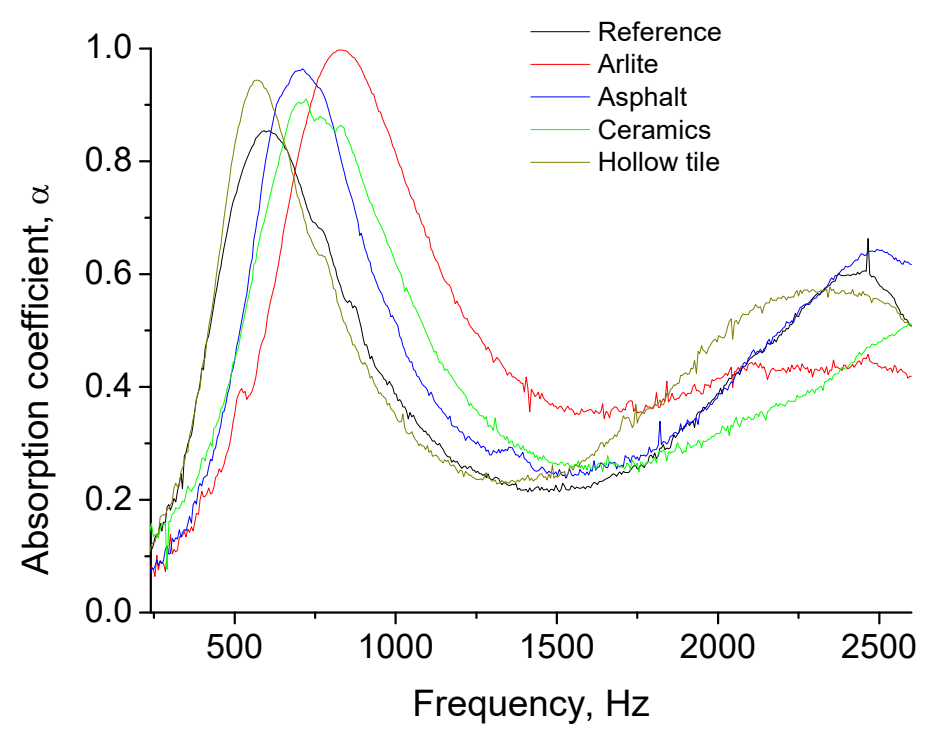

Figure 5: Absorption coefficient in the studied range of the non-compacted concrete samples prepared with each type of aggregates (including reference).

Two parameters will be considered to study the effectiveness of the sound attenuation on each set of samples. The maximum value of the absorption coefficient, $\alpha$, and the percentage of frequencies for which this factor is higher than 0.5 . This parameter would be used to study the amplitude in which the concrete could be used as an acoustic attenuator. Both parameters are shown in Table 4.

Table 4: Parameters obtained from the acoustic measurements on concrete samples.

\begin{tabular}{|l|c|c|c|}
\hline Material & Max $\alpha$ & $\% \alpha>0.5$ & Compacted \\
\hline \multirow{2}{*}{ Reference } & 0.85 & 36.43 & No \\
\cline { 2 - 4 } & 0.99 & 24.10 & Yes \\
\hline \multirow{2}{*}{ Arlite } & 0.997 & 26.92 & No \\
\cline { 2 - 4 } & 0.68 & 27.70 & Yes \\
\cline { 2 - 4 } Asphalt & 0.96 & 38.69 & No \\
\hline \multirow{2}{*}{ Ceramic } & 0.91 & 55.63 & Yes \\
\cline { 2 - 4 } & 0.91 & 26.70 & No \\
\hline \multirow{2}{*}{ EVA } & 0.86 & 39.86 & Yes \\
\hline \multirow{2}{*}{ Recyclow tiles } & 0.71 & 29.95 & Yes \\
\hline Rubber & 0.94 & 42.31 & No \\
\cline { 2 - 4 } & 0.58 & 16.21 & Yes \\
\hline
\end{tabular}

As it can be seen, there is a clear difference in the acoustic behaviour as a function of the type of aggregate used. Among the set of compacted materials, the one that shows a higher sound absorption is the reference material, but both rubber and asphalt present close values. 
The worst peak values are presented by the hollow tiles, the recycled concrete and the arlite. The first one shows these results, that can be clearly related to the higher density and lower porosity. In the rest of materials there seems to be no clear correlation between density and maximum acoustic attenuation.

Some of the non-compacted samples give attenuation factors bigger than 0.9 , and all the recycled materials under non-compaction conditions improve the maximum attenuation provided by the reference material. It is also clear that the tested materials improve the value of the maximum with respect to the compacted samples. From this point of view, it is possible to state that it is possible to use recycled aggregates for sound attenuation, and that it is better using non-compacted materials than using a manual compacting method.

Regarding the frequency range for which the attenuation factor is higher than 0.5 , when samples are compacted almost every material (excepting recycled concrete and hollow tiles) have a bigger bandwidth with effective sound attenuation, so, they can be used for a wider range of acoustic applications. When samples are non-compacted only hollow tiles and asphalt present a bandwidth broader than the reference. The behaviour of this parameter is quite erratic and some more research is required, because it has nothing to do with the density, with the maximum peak of sound absorption and not even with the type of material.

\subsection{Image analysis}

The results of the proposed image analysis for this study are presented in Table 5. The percentage of area corresponding to each type of hole, or surface, and the average area of all the pores measured for each mask applied on the image are presented. It has to be pointed out that the more reliable data are those of the deep pores, for which the program makes no assumption or correction. The mean diameter calculated for both surface and the intermediate region can have small differences with the reality due to the assumptions made by the algorithm used by the program. The analysis has only been done for the compacted samples, as a first attempt to establish a correlation with this analysis, and the authors have decided to take the complete set of materials tested.

In a first approach, the image analysis data (Table 5) indicates that the mixes made from arlite or rubber exhibit a higher percentage of area of deep pores (22-32\%) when compared to the others $(3.2-8 \%)$, being also the samples that showed a higher sound absorption peak (see Figs 4 and 5). These results were expected given that samples having deeper pores should yield higher viscothermal losses as the acoustic wave propagates throughout them and thus an increased sound attenuation [18]. It should be pointed out that even though the porosity of the rubber mixes (unfortunately, the porosity of the arlite mixes was not possible to measure) is not as high as that of the others, its sound absorption performance clearly exceeds that of the remaining mixes. In this regard, it is worth remarking that apart from the porosity, the microstructure of a porous material plays a key role in these dissipation phenomena. Hence, the results confirm the need to measure not only the porosity but also other parameters (e.g. flow resistivity, tortuosity...) for a more complete characterization and a better understanding of the acoustic behaviour of these concrete-based materials [19], [20].

However, some conclusions can be drawn from the presented results. The results show that the samples with higher contribution of the deep holes (more accessible deep holes) correspond to the samples prepared with arlite, rubber and asphalt. If instead of doing a global study we focus on the samples with materials coming from the same family, we would obtain more useful information. Starting with the aggregates that have an organic origin, rubber and asphalt were the materials that produced a higher absorption coefficient after the reference 
Table 5: Contribution of each pore type to the total surface.

\begin{tabular}{|l|l|c|}
\hline Material & Type of pore & \% area \\
\hline \multirow{4}{*}{ Reference } & Surface & 46.6 \\
\cline { 2 - 3 } & Intermediate & 50.2 \\
\cline { 2 - 3 } & Deep & 4.1 \\
\hline \multirow{4}{*}{ Asphalte } & Surface & 3.77 \\
\cline { 2 - 3 } & Intermediate & 63.66 \\
\cline { 2 - 3 } & Deep & 32.46 \\
\hline \multirow{4}{*}{ Ceramics } & Surface & 33.3 \\
\cline { 2 - 3 } & Intermediate & 58.2 \\
\cline { 2 - 3 } & Deep & 8.5 \\
\hline \multirow{3}{*}{ Hollow T. } & Surface & 42.9 \\
\cline { 2 - 3 } & Intermediate & 50.8 \\
\cline { 2 - 3 } & Deep & 6.3 \\
\hline \multirow{3}{*}{ Recycled Conc } & Surface & 50 \\
\cline { 2 - 3 } & Intermediate & 46.8 \\
\cline { 2 - 3 } & Deep & 3.2 \\
\hline & Surface & 39.8 \\
\cline { 2 - 3 } & Intermediate & 57 \\
\cline { 2 - 3 } & Deep & 3.2 \\
\cline { 2 - 3 } & Surface & 32.9 \\
\hline \multirow{3}{*}{ Rubber } & Deep & 63 \\
\cline { 2 - 3 } & Surface & 4.1 \\
\cline { 2 - 3 } & Intermediate & 23.3 \\
\cline { 2 - 3 } & Deep & 55.4 \\
\hline \multirow{3}{*}{} & & 21.2 \\
\hline
\end{tabular}

material (see Table 4), so it might indicate that the surface of deep holes has an influence on the sound attenuation, but there is also an effect of the type of material used. Looking at the materials prepared with cement-based materials wastes (recycled concrete, and hollow tiles) the same conclusion can be reached, the material with higher fraction of deep holes recycled concrete exhibits also a higher peak absorption of sound (0.68). The rest of the materials cannot be grouped in families, so we can say that for materials coming from the same type of waste, those that give a bigger volume of deep holes are the ones that are more effective for sound attenuation in terms of maximum absorption coefficient. This analysis has never been done, to the knowledge of the authors, and is quite innovative. Most of the papers dedicated to the study of the sound attenuation have tried different materials [21], [22] but no attention is usually paid to the relationship between pore or holes structure and acoustic properties.

Regarding the bandwidth for which the samples show an absorption coefficient higher than 0.5 , it is clearly not related neither to the deep holes nor to the intermediate holes, but a relationship can be established with the surface (blue coloured, with no apparent pore). Taking a look at the aggregates from organic origin (asphalt, EVA and rubber) EVA samples have the highest closed surface, and rubber has the lowest surface and the have an absorption coefficient higher than 0.5 namely 55.63 for asphalt 29.95 for EVA and 26.57 for rubber, so there is no clear correlation with the surface either. More research is required for the study 
of the effect of using recycled aggregates on the bandwidth where there is a significant sound attenuation.

But, with the provided results it can be concluded that the maximum absorption is a function of both the type of material used and the fraction of deep pores in the materials used to this end.

\section{CONCLUSIONS}

After the data measured and the analysis done the following conclusions can be drawn:

- The use of recycled aggregates strongly affects the values of density and pore fraction of the concrete samples prepared. The use or not of a compacting method also affects the values of density and porosity.

- The use of recycled aggregates also affects the acoustic properties of concrete. The recommendation of using non-compacted materials could be established since they provide a better sound absorption than the compacted ones.

- In terms of sound absorption it is possible to use recycled aggregates with total satisfaction, especially when the materials are non-compacted.

- The fraction of deep holes for each family of materials used as recycled aggregate can be used to predict the sound absorption. This parameter will be a function of the family of materials and the fraction of deep holes.

- The study of the bandwidth with an attenuation higher than 0.5 should be more studied in depth, because, with the provided results, it seems not to correspond to any of the parameters studied.

- Recycling of materials as aggregates for concrete that will be used as a sound isolator is possible, and it can improve the acoustic behaviour of the concrete with natural aggregates. This will improve the recycling rates, that should be increased according to the legislation, and give more sustainable materials, even though more research is necessary to understand completely their behaviour.

\section{ACKNOWLEDGEMENT}

The authors of this study would like to thank D. Manuel Iniesta Castillo for collaboration in the testing of samples.

\section{REFERENCES}

[1] European Parliament, Directive 2008/98/EC of the European Parliament and of the Council of 19 November 2008 on waste and repealing certain Directives. Off. J. Eur. Union, pp. 312-330, 2008.

[2] P. Comission for Concrete, Instrucción de hormigón estructural EHE-08. Structural Concrete Instruction, EHE-08, 2008.

[3] Mália, M., de Brito, J., Pinheiro, M.D. \& Bravo, M., Construction and demolition waste indicators. Waste Manag. Res., 31, pp. 241-55, 2013.

[4] Rodríguez, G., Medina, C., Alegre, F.J., Asensio, E. \& Sánchez de Rojas, M.I., Assessment of construction and demolition waste plant management in Spain: In pursuit of sustainability and eco-efficiency. J. Clean. Prod., 90, pp. 16-24, 2015.

[5] Rodríguez, C. et al., The incorporation of construction and demolition wastes as recycled mixed aggregates in non-structural concrete precast pieces. J. Clean. Prod., 127, pp. 152-161, 2016.

[6] Yang, J., Du, Q. \& Bao, Y., Concrete with recycled concrete aggregate and crushed clay bricks. Constr. Build. Mater., 25, pp. 1935-1945, 2011. 
[7] Rodríguez, C., Sánchez, I., Miñano, I., Benito, F., Cabeza, M. \& Parra, C., On the possibility of using recycled mixed aggregates and GICC thermal plant wastes in nonstructural concrete elements. Sustainability, 11, p. 633, 2019.

[8] Rodríguez, C., Miñano, I., Aguilar, M.Á., Ortega, J.M., Parra, C. \& Sánchez, I., Properties of concrete paving blocks and hollow tiles with recycled aggregate from construction and demolition wastes. Materials (Basel), 10, 2017.

DOI: $10.3390 / \mathrm{ma10121374.}$

[9] Sousa, J.G.G., Bauer, E. \& Sposto, R.M., Empleo de residuos de la construcción civil como áridos reciclados. Producción de bloques de hormigón. Mater. Constr., pp. 5970, 2003.

[10] Evangelista, L. \& de Brito, J., Mechanical behaviour of concrete made with fine recycled concrete aggregates. Cem. Concr. Compos., 29, pp. 397-401, 2007.

[11] Brand, A.S. \& Roesler, J.R., Bonding in cementitious materials with asphalt-coated particles: Part II - Cement-asphalt chemical interactions. Constr. Build. Mater., 130, pp. 182-192, 2017.

[12] AENOR, UNE-EN 197-1:2011. Composición, especificaciones y criterios de conformidad de los cementos comunes, 2000.

[13] AENOR, UNE-EN 12390-7:2009. Ensayos de hormigón endurecido. Parte 7: Densidad del hormigón endurecido (Testing hardened concrete. Part 7: Density of hardened concrete), 2009.

[14] ISO 10543-2:2002, Acoustics. Determination of sound absorption coefficient and impedance in impedance tubes. Part 2: Transfer function method, 2002.

[15] López Gayarre, F., Suárez González, J., Blanco Viñuela, R., López-Colina Pérez, C. \& Serrano López, M.A., Use of recycled mixed aggregates in floor blocks manufacturing. J. Clean. Prod., 167, pp. 713-722, 2018.

[16] Brand, A.S. \& Roesler, J.R., Bonding in cementitious materials with asphalt-coated particles: Part I - The interfacial transition zone. Constr. Build. Mater., 130, pp. 171$181,2017$.

[17] Evangelista, L. \& de Brito, J., Mechanical behaviour of concrete made with fine recycled concrete aggregates. Cem. Concr. Compos., 29, pp. 397-401, 2007.

[18] Allard, N. \& Atalla, J.F., Propagation of Sound in Porous Media: Modelling Sound Absorbing Materials. John Wiley \& Sons: UK, 2009.

[19] Vašina, M., Hughes, D.C., Horoshenkov, K.V. \& Lapčík, L., The acoustical properties of consolidated expanded clay granulates. Appl. Acoust., 67, pp. 787-796, 2006.

[20] Horoshenkov, K.V., Hughes, D.C. \& Cwirzen, A., The sound speed and attenuation in loose and consolidated granular formulations of high alumina cements. Appl. Acoust., 64, pp. 197-212, 2003.

[21] Herrero, S., Mayor, P. \& Hernández-Olivares, F., Influence of proportion and particle size gradation of rubber from end-of-life tires on mechanical, thermal and acoustic properties of plaster-rubber mortars. Mater. Des., 47, pp. 633-642, 2013.

[22] Ghizdăveț, Z., Ștefan, B.M., Nastac, D., Vasile, O. \& Bratu, M., Sound absorbing materials made by embedding crumb rubber waste in a concrete matrix. Constr. Build. Mater., 124, pp. 755-763, 2016. 